\title{
Stigma of Epilepsy among Patients and their Relatives Attending Charity Clinic, Omdurman-Sudan, June, 2012
}

Mohamed A Taha, Siham Ahmed Balla, Abbashar M Hussien*and Mohamed D Dafaalla

Department of Medicine, University of Khartoum, Sudan

*Corresponding author: Abbashar M Hussien, Department of Medicine, University of Khartoum, Sudan, E-mail: abbashar59@yahoo.com

Received date: May 26, 2014, Accepted date: Sep 06, 2014, Published date: Sep 15, 2014

Copyright: (c) 2014 Taha MA, et al. This is an open-access article distributed under the terms of the Creative Commons Attribution License, which permits unrestricted use, distribution, and reproduction in any medium, provided the original author and source are credited.

\begin{abstract}
Epilepsy is the world's most common and most serious chronic neurological disease affecting near 50 million people. Epilepsy has a well-recognized stigma which is defined by Link and Phalen as a status which exists when elements of labeling, stereotyping, separation, status loss, and discrimination occur together in a power situation that allows them to unfold. Stigma has a major contribution to the reduction of quality of life in people with epilepsy.
\end{abstract}

Objectives: The purpose of this study was to determine the types of stigma types, frequency, its association with demographical factors, and the coping ability in PWE.

Methods: Health facility-based case-series analytical study was conducted on 80 patients with epilepsy aged from 8-70 years attending Dr. Abbashar Hussein's charity clinic in Om-Durman city. Verbal consent was obtained from the patients and a standardized questionnaire was used for the interview of the patients. Assistance was occasionally asked from their relative. Statistical analysis was performed using SPSS version 16.

Results: $16.3 \%$ were found to have a positive felt stigma score. Nearly half of PWE had courtesy stigma, also coaching stigma affected half of PWE. One fifth of PWE had poor coping score. Age below forty was found to be a determinant factor for the coping of people with epilepsy as well as courtesy stigma. Frequency of seizures of more than 3 per month reduced coping score of PWE.

Conclusion: The results suggest the great need for psychological counseling for high risk groups of PWE.

\section{Introduction}

Epilepsy is the world's most common and most serious chronic neurological disease affecting nearly 50 million people world-wide [1] The impact of the disease on patients is divided into two categories: biomedical and psychological impact [2]. The biomedical impact includes the characteristics of seizure, side effect of anti-epileptic drugs (AEDs), cognitive, behavioral and emotional co-morbidities [2].

Stigma has been defined by Link and Phalen as a status which exists when elements of labeling, stereotyping, separation, status loss, and discrimination occur together in a power situation that's allows them to unfold [3]. In other words, stigma is the carriage of the heaviness of the disease and the burden of being labeled as inferior or infected by others who are healthier and in a better (power) situation to label the diseased person, causing them the loss of and their status in the community [3]. Stigma passivity and hence its importance occur due to the impact on quality of life (QOL) and psychological status [4]. Reduction in QOL: It starts with their families, then their childhood life, adolescence, and finally adulthood (family $\rightarrow$ childhood $\rightarrow$ adolescence $\rightarrow$ adulthood). Families dealing with children with epilepsy (CWE) can be very stressful which affect the whole family environment and disrupts parenting behavior, making them more restrictive. Children with epilepsy (CWE) are also at risk of academic underachievement which is the major contributor to having a negative attitude towards the disease. All of these factors ,along with the coexisting stigma, type of seizure, and medication, result in patients having low self-esteem, making them feel incompetent in their society and unable to form normal bonds with reference group (children in class room, siblings) [5].

During the period of adolescence, patients become more sensitive from other people comments and become increasingly self-reflective, leading to reduction of social habits and events, resulting in social isolation and behavior abnormalities [4]. Barriers persist in adulthood, reflected by lower chances to get employed or to get married, in addition to previous mentioned social isolation and interestingly stigmatized females are more prone for sexual abuse [6]. Thus, stigma has a major influence to QOL, as described by Jacoby A:"to have epilepsy is to open oneself to the full force of past and contemporary social prejudice and misunderstanding" [1]. Impaction on Psychological status: it is well recognized that stigma can cause major psychological disorders in people with epilepsy (PWE) like anxiety, depression, frustration and anger, and other behavioral problems which are associated with epilepsy like attention deficit hyperactivity disorder and cognitive impairment [4].

Patient-perceived stigma in PWE has been grouped into four main categories: enacted, felt in patients coaching courtesy in their parents and relatives [1]. Enacted stigma refers to actual discrimination episodes against PWE due to their medical condition, i.e. it occurs when others -due to various reasons- label, name, or act discriminatively towards PWE. It is mainly due misconceptions and poor knowledge about the disease. Many fear PWE, thinking it to be a 
Page 2 of 6

sin or demonic possession. Others think epilepsy is contagious [6]. Felt stigma is defined as the shame of being epileptic and the oppressive fear of encountering enacted stigma. It is the commonest type of stigma and likely to occur without enacted stigma (due to increased knowledge about epilepsy in societies and improved practice towards PWE) [1]. Coaching stigma occurs in ashamed parents who tend to teach their children that epilepsy is an undesired differentness or a moral weight they have to carry [1]. On the other hand, courtesy stigma is the sense of shame that spread from the labeled individual to their parents or families [1]. According to all stigmas in PWE mentioned before; individuals acted differently and thus have been divided into many categories as de fined by Jacoby A [1]. Firstly; it was categorized according to the apparent stigma status into stigmatized people whom are discredited (patients whose differentness is selfevident) and into dis creditable (patients whose differentness is not immediately apparent but can be potentially stressed by labeling and actions of others). Secondly; it was categorized according to the response and behavior of PWE towards their stigma into unadjusted (patients who are overwhelmed by their stigma and saw it as a limiting burden to achieve personal and social success) and to adjusted (patients who have some control on their behavior and emotions towards their disease and stigma) [1].

\section{Objectives}

General: To study the stigma among patients with epilepsy and their relatives attending Dr.Abbasher's charity clinic in OmdurmanSudan 2012

Specific: To determine the type and frequency of stigma among patients with epilepsy and their parents/relatives.

To determine the association between stigma and demographical and demographical and biomedical factors and other types of stigma.

To determine the response and coping ability of PWE towards their stigma.

\section{Materials \& Methods}

\section{Study design: Case-series analytical study}

Study area: Khartoum state (capital of Sudan); It's a charity outpatient clinic for neurological patients, dedicated mainly / attended majorly by epileptic patients. It receives patients on Friday nights, coming from different parts of the state even from out-side the Khartoum state. Most of the patients attending the clinic are of moderate to poor social

Study population: Inclusion criteria: people diagnosed with epilepsy of any type according to the International League against Epilepsy (ILAE), aged between 8 and 70 years.

Exclusion criteria: Age below 8 years who are not epileptic (perception of stigma of children less than 8 years is incomplete and not yet developed [2], and age above 70 years (more likely to have recall bias due senile memory and cognition impairment.

Size: 80 patients were interviewed, based on the prevalence of epilepsy of WHO in Sub-Saharan countries, which ranges from 2.2/1000 to 58/1000 (as mentioned in "Epilepsy in the WHO African region, the global campaign against epilepsy " out of the shadows "; prevalence ; page 5-6 ). The upper limit was taken0.05. Sample size was measured by the following equation:

\section{$Z^{2} p q / a^{2}+10 \%$}

$\mathrm{Z}=1.95$ in $95 \%$ confidence interval, p: prevalence of stigma in PWE, $q=1-p$, a: alpha error of the study equals $0.05,10 \%$ are the none responders

\section{Sample selection:}

\section{Tools and methods:}

Analysis: SPSS version 16 was used for data entry and analysis using cross-tabulation and chi-square with $\mathrm{p}$ value significant level less than or equal to 0.05 .

Analysis plan: Standardized scoring system was used to assess the felt score, composed of 3 Yes/No questions; yes was given 1 point and no was given zero. Scores of 0 or 1 were considered felt-stigma free patients, while scores of 2 or 3 are considered felt-stigma positive patients.6, 8, 9, 10 Enacted score was created by the author, composed of 7 questions, and was used to assess enacted stigma by the community towards every patient. The score ranges from zero to 7 , zero to 2 is considered not having Enacted stigma, 3 or more is considered to have positive enacted stigma.

Ethical Consideration:Only PWE who agreed to participate was included in the study, verbal consent was taken from PWE before the interview. The interviewer introduced himself first then gave a brief explanation about the study for each participant.

\section{Results}

Of the eighty PWE $(\mathrm{N}=80)$ interviewed, $54 \%$ were males. $35 \%$ of age $8-15$ yrs and $60 \%$ were below 21 yrs. $40 \%$ were at primary school level, and $11 \%$ dropped out of school. $65 \%$ had generalized tonic-clonic seizures and $11 \%$ had pseudoepilepsy. $85 \%$ had $1-3$ seizures per month and $15 \%$ had more than 3 seizures / month. $60 \%$ reported no history of significant trauma, and $19 \%$ had visible stigmata that was noted by the interviewer. Almost all the PWE were on medications, $83 \%$ of which were using Sodium Valproate and the rest using carbamazepine.

\section{Felt stigma}

Almost 16.3\% were found to have a felt stigma score of 2 or more points indicating a high perception of felt stigma. No statistical association was found between felt stigma score and studied variables: gender, age, education, type of epilepsy, frequency, significant trauma, medication, stigmata, enacted stigma or parental stigma, as shown in Table 1.

\begin{tabular}{|l|l|l|l|}
\hline \multicolumn{4}{|l|}{ Felt stigma-score } \\
\hline & not stigmatized & stigmatized & Total\% \\
\hline male & $83.70 \%$ & $16.30 \%$ & $100 \%$ \\
\hline female & $83.80 \%$ & $16.20 \%$ & $100 \%$ \\
\hline
\end{tabular}

Table 1: Felt stigma score and gender.

Study conducted at charity clinic, Omdurman-Sudan, June-July, 2012. P value: $1.000(>0.05)$. 
Page 3 of 6

\section{Enacted stigma}

$12.5 \%$ of the patients thought that their communities believed epilepsy was contagious. $56.2 \%$ thought epilepsy was due to demon possession. $13 \%$ mentioned people were afraid from them when they were having seizures in public and hence they don't help them. $11.5 \%$ mentioned their communities knew about their condition against their will compared to $77.4 \%$ who voluntary told their communities and $11 \%$ no one in their communities knew they had epilepsy and they keep it as secret. $22 \%$ of 40 PWE mentioned that their teachers acted badly towards them. About half of 19 PWE mentioned that they had lost an employment chance only because of their epilepsy, and $3(16 \%)$ lost marriage proposal only because of their epilepsy. $9 \%$ had a positive enacted score. Only the frequency of seizures was found to be statistically associated with enacted score $(\mathrm{P}<0.05)$, (Table 2$)$.

\begin{tabular}{|l|l|l|}
\hline Frequency per month & Not stigmatized & Stigmatized \\
\hline 3-Jan & $94.10 \%$ & $5.90 \%$ \\
\hline$>3$ & $75.00 \%$ & $25.00 \%$ \\
\hline
\end{tabular}

Table 2: Enacted score and frequency of seizures.

Study conducted at charity clinic, Omdurman-Sudan, June-July, 2012. $P$ value: $0.031(<0.05)$, Odd ratio $=5$

\section{Parents-Relatives stigma}

It was found that $47.5 \%$ of PWE had coaching stigma and $45 \%$ had courtesy stigma. Age was the only variable that showed statistically association with coaching stigma (Table 3). Coaching stigma percentage decreases over age till the age of 30 , then rises in age interval 31-40, and decreased again above age of 40's.

\begin{tabular}{|l|l|l|}
\hline Coaching stigma & No & Yes \\
\hline Age Group & $32.10 \%$ & $67.90 \%$ \\
\hline 8 yrs-15 & $55.00 \%$ & $45.00 \%$ \\
\hline $16-20$ & $72.70 \%$ & $27.30 \%$ \\
\hline $21-30$ & $54.50 \%$ & $45.50 \%$ \\
\hline $31-40$ & $80.00 \%$ & $20.00 \%$ \\
\hline$>40$ & &
\end{tabular}

Table 3: Coaching stigma and Age.

Study conducted at charity clinic, Omdurman-Sudan, June-July, 2012. $\mathrm{P}$ value $=0.049(<0.05)$.

\section{Coping Assessment}

The study showed that $16.2 \%$ thought their epilepsy was a moral weight they could bear to live with. $22.8 \%$ always felt stressed about their condition, $28.8 \%$ felt that secrecy was the best way to handle their condition. Coping score was calculated by summation of previous 3 questions and any patient with 2 or more score is considered to have poor coping with the disease. $19 \%$ had poor coping-score. Coping score was found to have a statistical associated with three variables, namely the: age of the patient, frequency of seizure, and courtesy stigma. Age significantly affected the coping score (Table 4), there was an increase in coping score (poor coping) as the age increase (except the age interval between 16 to 20 yrs.) till reaching the forties where all PWE showed good coping score.

\begin{tabular}{|l|l|l|l|}
\hline & \multicolumn{3}{|c|}{ COPE score } \\
\hline \multirow{4}{*}{ Age group } & & Good coping & poor coping \\
\cline { 2 - 4 } & 8 yrs-15 & $78.60 \%$ & $21.40 \%$ \\
\cline { 2 - 4 } & $16-20$ & $95.00 \%$ & $5.00 \%$ \\
\cline { 2 - 4 } & $21-30$ & $72.70 \%$ & $27.30 \%$ \\
\cline { 2 - 4 } & $31-40$ & $54.50 \%$ & $45.50 \%$ \\
\cline { 2 - 4 } & $>40$ & $100.00 \%$ & $0.00 \%$ \\
\hline
\end{tabular}

Table 4: Cope score and Age.

Study conducted at charity clinic, Omdurman-Sudan, June-July, 2012. P value: $0.032(<0.05)$.

\section{Frequency of seizures:}

Frequency of seizures significantly associated with 3 factors; Adjustment, discredited status, and the coping score as follows. Half of PWE with more than 3 seizure s/month thought epilepsy was hindrance that prevented them from normal life compared to only to $10 \%$ who had three or lesser attacks/ month. 54\% PWE with $>3$ seizures/month were discredited about their condition compared with only $17 \%$ with 1 -3attacks/month were discredited (Table 5). 50\% PWE with $>3$ attacks/month had poor coping and only $13 \%$ with $1-3$ seizure/month had poor coping (Table 6).

\begin{tabular}{|c|c|c|c|c|c|c|}
\hline \multirow{2}{*}{$\begin{array}{l}\text { Frequency } \\
\text { per month }\end{array}$} & \multicolumn{2}{|c|}{ discredited status } & \multicolumn{2}{|c|}{ COPE score } & \multicolumn{2}{|c|}{ Adjustment } \\
\hline & discredited & $\begin{array}{l}\text { good } \\
\text { coping }\end{array}$ & $\begin{array}{l}\text { good } \\
\text { coping }\end{array}$ & $\begin{array}{l}\text { poor } \\
\text { coping }\end{array}$ & Adjusted & $\begin{array}{l}\text { Not } \\
\text { adjusted }\end{array}$ \\
\hline 3-Jan & $17.60 \%$ & $86.80 \%$ & $86.80 \%$ & $13.20 \%$ & $89.70 \%$ & $10.30 \%$ \\
\hline$>3$ & $54.50 \%$ & $50.00 \%$ & $50.00 \%$ & $50.00 \%$ & $50.00 \%$ & $50.00 \%$ \\
\hline
\end{tabular}

Table 5: discredited status, COPE score, and Adjustment vs. frequency of seizure.

Adjustment, discredited status, and COPE score P values are 0.001 , 0.007 , and 0.003 respectively. The Odd ratios are: $8.7,5$, and 6.5 . Study conducted at charity clinic, Omdurman-Sudan. June-July, 2012.

\section{Courtesy stigma}

Courtesy stigma affects significantly the cope score (Table 6). High association between courtesy and cope-score was found, showing that having courtesy stigma will make the patient four times more likely to have poor coping with the disease. $30.6 \%$ of PWE with courtesy stigma didn't cope well with the disease compared to $9 \%$ whom didn't have courtesy stigma. Felt score didn't affect cope score significantly (Table 7). Only 3 patients received psychological counseling about their condition.

\begin{tabular}{|l|l|l|}
\hline \multirow{2}{*}{ Courtesy stigma } & \multicolumn{2}{|l|}{ COPE score } \\
\cline { 2 - 3 } & good coping & poor coping \\
\hline
\end{tabular}




\begin{tabular}{|l|l|l|}
\hline no & $90.90 \%$ & $9.10 \%$ \\
\hline yes & $69.40 \%$ & $30.60 \%$ \\
\hline
\end{tabular}

Table 6: Courtesy stigma and Cope score.

\begin{tabular}{|l|l|l|}
\hline \multirow{2}{*}{ Felt score } & \multicolumn{2}{|l|}{ COPE score } \\
\cline { 2 - 3 } & good coping & poor coping \\
\hline not stigmatized & $83.60 \%$ & $16.40 \%$ \\
\hline stigmatized & $69.20 \%$ & $30.80 \%$ \\
\hline
\end{tabular}

Table 7: Felt score and Coping score.

Study conducted at charity clinic, Omdurman-Sudan, June-July, 2012. P value: $0.25(>0.05)$

\section{Discussion}

\section{Felt stigma}

The study showed $16.3 \%$ of patients having positive felt stigma based on the felt stigma score. This percentage is considered to be low compared to other developed communities like Netherlands (30\%), Poland (56\%) and France (62\%) [3], lower than what was mentioned by MARJU R A and Sang-Ahm Lee $[8,9]$ but nearly similar to results reported by Jacoby A. [1,8,9] Although these communities have a higher education level that can prevent stigmatizing actions and relieves fear and sense of shame from PWE, still the attitude didn't change. These findings could be explained by the following:

A. Religion may play a central role in the perception of felt stigma. Most of PWE in this study always mentioned religious causes to accept their disease and its consequences, they mentioned that "disease is God's decision so we don't argue or be ashamed from that".

B. Sudanese community has great friendly bonds between diseased patients and other healthier persons, this may overcome the fear and shame felt by patients. But that may not be the case, however, as the felt stigma by definition occurs in the absence of external labeling and stigmatizing actions.

C. Higher standards of living in these communities raise the selfperception and inner image of wellbeing to cope with community, so when people get chronic debilitating disease they may be concerned and fear losing their status in their communities.

Age and gender didn't show marked difference on perception of felt stigma similar to study done by Masharip Atadzhanov $\mathrm{AH}$, and another one done by Sang-Ahm Lee H-JY [3,9]. However, it differed from what was mentioned by Paula T [10], in which they found gender to be a contributing factor for perception of stigma; females were more prone to develop felt stigma. This is perhaps due to the large sample size of that study [1850 samples] that may have given the association between gender and felt score which this study and many other studies failed to confirm $[3,9,10]$. Type of seizure didn't affect the felt score outcome in this study, which is similar to what was mentioned by Masharip Atadzhanov AH and by Paula T [3,9], but unlike what was reported by MARJU RA[8]. Although categorized into "with and without" loss of consciousness, also to true and false seizure as well as simple versus generalized, all of them didn't show significant differences. [3,8,9]. Furthermore, frequency of seizures didn't affect felt stigma perception like what was mentioned d by Masharip and Marju RA [3,8], but unlike what was reported by Gigi smith PLF and Sang-Ahm Lee H-JY [7,9]. Type of medication and education level also failed to show significant difference on perception of felt stigma similar to what was mentioned by Sang-Ahm Lee H-JY [9], but Paula $\mathrm{T}$ and his colleagues showed school level as a determinant factor for felt stigma [10].

The relation between felt and enacted stigma was tested to measure how enacted stigma will influence felt stigma perception. However, this study failed to demonstrate significant association. Actions of community didn't (significantly) influence the felt stigma perception and this may be explained as felt stigma, by definition, is the shame felt in the absence of real external stigmatizing actions or behaviors, although enacted on long term may teach PWE to bear fear and shame even in the absence of real stigmatizing actions (i.e., enacted effect on stigma may have long lag period so PWE would learn to be shamed from their status).

\section{Enacted stigma}

Enacted stigma was approached by multiple questions seeking the attitude of the community towards PWE. These questions were not asked directly to the community members as the goal here was the perception of PWE of the actions done by the community on them. These questions were about demon possession, contagiousness, disclosure, teacher actions on school, job and marriage refusal. More than half of PWE thought their community considered epilepsy was caused by demon possession. These misbelieve may indicate:

1. A tendency to stigmatize PWE and reject them from normal social life and events.

2. High level of false concepts indicates poor level of education in community, so there is a chance of having other misbelieves about the same disease.

Contagiousness is a key component in enacted stigma. About $12 \%$ of PWE in this study though $t$ that their community deals with their disease as a contagious disease, meaning that the withdrawal action and fear from getting the disease noticed by PWE increases their stigma and lower their inner self-image. More than two thirds of PWE voluntary shared the information of their disease with their community without concealment, which is a good indicator pointing the ease of communication with their surroundings. On the other hand, one third hid their condition from their community, and some of them mentioned that their communities knew their condition against their will, which indicates the presence of fear from being labeled as well as positive enacted actions done by their communities. Other parameters such as teacher behavior towards the epileptic patient were good and not stigmatizing in eighty percent of PWE in school age. This parameter is important as many types of epilepsy may influence the school performance by mental disabilities or loss of consciousness like in absent seizure. This requires informing teachers to not act in a way that could worsen the self-image of PWE and blame them for school deteri oration. Loss of job and rejection on marriage proposal also may be explained by enacted action $\mathrm{s}$ by the society and reflects fear as well as poor education about this condition. As over all, only nine percent of PWE gave positive enacted stigma score, this outcome is considered not representative and lower than expected. This may be due to: 
Page 5 of 6

1- $\quad$ The study sample size may be small and doesn't show the real magnitude of enacted stigma

2- $\quad$ Many patients were young so actions like job loss or marriage refusals were not asked.

3- The high percentages of demon possession and contagiousness misconceptions indicate the great magnitude of enacted stigma that cannot be only nine percent.

Frequency of seizures significantly affected the enacted score (Table 2), that may be explained as follows: the more PWE had seizures, the more likely they would lose their concealing ability and will not be able to hide their disease thus being more prone for stigmatizing actions by others and labeling them as "undesired differentness". Gender was not a determinant factor for occurrence of enacted stigma, meaning the communities didn't recognize PWE as "male" or "females" so to act in stigmatizing matter toward them.

\section{Parents related stigma}

One of two PWE has courtesy stigma and this is also true about coaching stigma. Parents affect a great deal of PWE's lives theoretically from felt perception till how these patient cope with the disease. This high percentage indicates the excessive worry of parents, that also mean the presence of a person who is constantly reminding PWE about their condition (i.e. do that, don't do this, don't play outside etc.). Age of PWE affected significantly the magnitude of coaching stigma (Table 3). By definition coaching (from the word coach, the man who tells you what to do) is the orders and actions done by parents toward their PWE to act in a manner that indicates that they have a stigmatizing disease like epilepsy, so as the PWE get older, they will not be under pa rents orders and they will gain their own existence to behave as they like. Younger PWE were more prone to be under coaching by their parents. On the other hand, age didn't influence courtesy stigma as age or duration may not change the shame that felt by parents toward their children.

Being male or female didn't show significant difference in parents' stigma that means parents didn't treat their children discriminately based on their gender. None of other studies showed percentage of neither courtesy nor coaching stigma.

\section{Coping ability of PWE}

About one third of PWE prefer to conceal their condition in order to gain normality. This is lower than what was reported by Westbrook LE and his colleagues; half of their patients made their condition secret from others (1). The importance of secrecy as a coping mechanism is as follows:

1. Secrecy means the relief from enacted stigma done by the community, so when there are no flags of the disease above PWE heads then the community will deal with them as normal ones and regain their normal quality of life QOL.

2. Secrecy statistically didn't affect the perception of felt stigma as well as courtesy or coaching stigma. Furthermore, it may increase the felt perception theoretically as the fear from been discovered. The obsession of having an attack in public may further stress the PWE. Therefore, secrecy is not considered to be a good coping strategy for long term.

One fifth of the PWE have poor cope score. Those patients always feel stressed at public, and they always think about epilepsy as a burden to their lives and prefer secrecy to regain normality. Felt stigma for instance failed to show significant statistical difference on the coping ability of the PWE (Table 7) (as P value more than significant level) although there is marked observational difference as $30 \%$ of those experiencing felt stigma had poor coping score compared with only $16 \%$ of those who did not experience felt stigma with poor coping ability. Here, the sample size of the study may not reflect the obvious theoretical association between felt stigma and coping ability. On the other hand, one of the most interesting and significant findings of this study was the association between courtesy stigma and coping ability of PWE . 30\% of positive courtesy PWE had poor coping score compared with only $9 \%$ not having courtesy stigma but with poor coping score, as shown in Table 6. Having courtesy stigma will increase the risk to get poor coping ability of the patient by 4 times. That may cause deep sensation of shame and guilt in PWE, and the carriage of these feelings would make them less capable of dealing with the disease in contrast to more helpful and more cheerful parents. No other study used cope score and compared it with courtesy stigma.

\section{Frequency of seizures}

Frequency of seizures was found to be a major variable affecting three factors; adjustment (Table 5), discredited status (Table 6) and coping score (Table 7). The poor controllability of seizures means less concealabilty and patients become discredited at all times instead of discreditable just when someone label them, similar to what was found in study [10]. Coping ability was the same according to gender. Age affected the coping ability of PWE (Table 4), the older they got, the better coping ability they could have. This may be explained as epilepsy usually starts at younger ages, so older PWE would have longer duration with the disease, discovering new method and techniques to live with the disease compared to younger ones.

\section{Recommendations}

Counseling ideally should be provided for every PWE on their first visit as well on regular routine follow-ups. Special attention should be made for high risk groups:

1- Any patient should be asked the three standardized questions of felt stigma while taking medical history. As well as their parents.

2- Coping ability should be determined for every patient by the appropriate questions.

3- $\quad$ Every patient with more than 3 seizures per month should receive appropriate psychological counseling.

4-Any patient with courtesy stigma in his parents should receive appropriate psychological counseling as well as his parents.

5- Patients less than forty years of age should receive appropriate psychological counseling with their parents at least ones as they are more prone to couching stigma as well as poor coping ability.

6- $\quad$ Appropriate education for the community, parents and PWE shall reduce the stigma perception and wrong concepts as well increasing the QOL of PWE and enable them to live their normal lives again.

\section{References}

1. Jacoby A (2002) Stigma, epilepsy, and quality of life. See comment in PubMed Commons below Epilepsy Behav 3: 10-20.

2. Gabriel M. Ronen DLS, Leonard H. Verhey, LucynaLach, Michael H. Boyle, Charles E. Cunningham m, et al. (2010) Disease characteristics 
Citation: Taha M, Balla S, Hussien A, Dafaalla M (2014) Stigma of Epilepsy among Patients and their Relatives Attending Charity Clinic, Omdurman-Sudan, June, 2012. J Neurol Neurophysiol 5: 224. doi:10.4172/2155-9562.1000224

Page 6 of 6

and psychological factors: Explaining the expression of quality of life in childhood epilepsy. Epilepsy \& behavior 18: 88-93.

3. MasharipAtadzhanov AH, Elwyn N. chomba, Edward K. Mbewe, Gretchen LanoBirbeck (2010) Epilepsy-associated stigma in Zambia: What factors predict greater felt stigma in a highly stigmatized population? Epilepsy \& behavior 19: 4148 .

4. Elliott IM, Lach L, Smith ML (2005) I just want to be normal: a qualitative study exploring how children and adolescents view the impact of intractable epilepsy on their quality of life. See comment in PubMed Commons below Epilepsy Behav 7: 664-678.

5. Rodenburg R, Wagner JL, Austin JK, Kerr M, Dunn DW (2011) Psychosocial issues for children with epilepsy. See comment in PubMed Commons below Epilepsy Behav 22: 47-54.

6. Baskind R, Birbeck GL (2005) Epilepsy-associated stigma in sub-Saharan Africa: the social landscape of a disease. See comment in PubMed Commons below Epilepsy Behav 7: 68-73.
7. Smith G, Ferguson PL, Saunders LL, Wagner JL, Wannamaker BB, et al. (2009) Psychosocial factors associated with stigma in adults with epilepsy. See comment in PubMed Commons below Epilepsy Behav 16: 484-490.

8. Rätsepp M, Oun A, Haldre S, Kaasik AE (2000) Felt stigma and impact of epilepsy on employment status among Estonian people: exploratory study. See comment in PubMed Commons below Seizure 9: 394-401.

9. Lee SA, Yoo HJ, Lee BI; Korean QoL in Epilepsy Study Group (2005) Factors contributing to the stigma of epilepsy. See comment in PubMed Commons below Seizure 14: 157-163.

10. Fernandes PT, Snape DA, Beran RG, Jacoby A (2011) Epilepsy stigma: what do we know and where next? See comment in PubMed Commons below Epilepsy Behav 22: 55-62. 